\title{
Hierarchical Decision Making Framework for Evaluation and Improvement of Composite Systems (Example for Building)
}

\author{
Mark Sh. LEVIN \\ Institute for Information Transmission Problems, Russian Academy of Sciences \\ 19 Bolshoj Karetny lane, Moscow, 127994, Russia \\ e-mail:mslevin@acm.org
}

Moshe A. DANIELI

The College of Judea \& Samaria

Ariel 44837, Israel

Received: June 2004

\begin{abstract}
The article describes a hierarchical decision making framework for the evaluation and improvement/redesign of composite systems. The framework is based on Hierarchical Morphological Multicriteria Design (HMMD) and corresponding morphological clique problem which realize "partitioning/synthesis macroheuristic". The system evaluation process consists in hierarchical integration of expert judgment (as ordinal estimates): a method of integration tables or the abovementioned morphological approach. As a result, ordinal multi-state classification is realized. The system improvement/redesign process is examined as the selection and planning of redesign operations while taking into account operations attributes (e.g., required resources, effectiveness) and binary relations (equivalence, complementarity, precedence) on the operation sets. For modeling the system improvement process several combinatorial optimization models are used (knapsack problem, multiple choice problem, etc.) including HMMD.

The suggested approach is illustrated by realistic numerical example for two-floor building. This applied problem is examined from the viewpoint of earthquake engineering.
\end{abstract}

Key words: engineering design, system analysis, composite systems, evaluation, improvement, multicriteria decision making, combinatorial optimization, morphological analysis, macroheuristic, civil engineering, earthquake engineering.

\section{Introduction}

\subsection{Evaluation and Improvement of Composite Systems}

Design, evaluation, and improvement/redesign of complex systems involve a wide range of tasks and cover all stages of products/systems life cycles (Aiello et al., 2002; Buede, 1999; Dixon, 1987; Finger and Dixon, 1989; Hazelrigg, 1996; Hubka and Eder, 1988; Kusiak, 1999; Otto and Wood, 2000; Pahl and Beitz, 1996; Ulrich and Eppinger, 1999). 
It is reasonable to point out the following main contemporary technological tendencies in the engineering of complex systems and products:

1. Consideration of the system design processes on the basis of hierarchical decision making technology (Hazelrigg, 1996; Hubka and Eder, 1988; Kuppuraju et al., 1985; Levin, 1998).

2. Examination of several system/product generations including: (1) system analysis on the basis of new customer needs; (2) revelation of bottlenecks in existing systems; (3) improvement/redesign of the system while taking into account new needs, e.g., sociotechnological needs, environmental needs (Berman et al., 1994; Bertero, 1992; Beskow and Ritzen, 2000; Chakravarti, 1999; Davidovici, 1993; Dixon and Colton, 2000; Du Bois et al., 1989; Engelhardt, 2000; Fogliatto and Albin, 2001; Forster et al., 1995; Fothergill et al., 1995; Gunasekaran et al., 1994; Hameri and Nihtila, 1998; Knosala and Pedrycz, 1992; Levin, 1998; Levin and Danieli, 2000; Marino, 1997; Miyasato et al., 1986; Ozer, 1999; Soebarto and Williamson, 2001; Stumptuer and Wotawa, 2001; Tenner and Detoro, 1996; Ulrich and Eppinger, 1999; Yerramareddy and Lu, 1993; Zakarian and Kusiak, 2001).

3. Usage of a modular approach as modular engineering, modular design (Baldwin and Clark, 2000; Ericsson and Erixon, 2000; Ganza, 1999; Hamlin and Sanderson, 1998; Huang and Kusiak, 1998; Hop, 1988; Hutchings, 1996; Jones, 1981; Kamrani and Salhieh, 2000; Levin, 1998). This trend is based on several reasons as follows:

1. Many systems and products are composite ones (e.g., in car industry, in aerospace industry). As a result, modular approach is very prospective from the viewpoints of life cycle engineering and product platform design (Ericsson and Erixon, 2000; Gonzalez-Zugasti et al., 2000; Kusiak, 1999; Simpson et al., 2001),

2. Modular system structure is very good basis to the use of many hierarchical decision making frameworks (including the use and acquisition of expert information) for the system analysis and design (Hubka and Eder, 1988; Levin, 1998; Stumptuer and Wotawa, 2001; Yerramareddy and $\mathrm{Lu}, 1993$ ).

4. Study of the system evaluation and improvement/redesign problems (Aiello et al., 2002; Berman et al., 1994; Beskow and Ritzen, 2000; Bowman et al., 2000 Chakravarti, 1999; Dixon, 1987; Dixon and Colton, 2000; Engelhardt, 2000, Forster et al., 1995; Fothergill et al., 1995; Gunasekaran et al., 1994; Hameri and Nihtila, 1998; Kusiak, 1999; Levin, 1998; Otto and Wood, 2000; Ozer, 1999; Soebarto and Williamsson, 2001; Tenner and Detoro, 1996; Yerramareddy and Lu, 1993; Zakarian and Kusiak, 2001).

Our article focuses on the above-mentioned two problems: (1) system evaluation and (2) system redesign/improvement. In the case of composite multidisciplinary systems, these problems are complicated and involve the following: (i) various system parts (for the system components), (ii) a crucial role of experts and their experience, (iii) a fundamental on the basis of previous situations and previous solved problems; and (iv) the coordination of the above-mentioned efforts (i.e., evaluation processes for system components, coordination of experts, analysis and usage of previous results, etc.). On the other words, it is necessary to take into account several "dimensions" of the problem solving process as follows: (a) system components and their interconnection; (b) time; (c) kinds 
of possible solving procedures (e.g., expert judgment, models, simulation); (d) kinds of information support, e.g., design case studies, some special engineering spaces and their combinations, engineering history data bases, knowledge bases; (d) coordination of the procedures and information into a resultant solving process. Moreover, different research methods can be used for different system components and for different parts of the problem solving process. The problem of integration of local decisions for system components/for local situations into a global decision plays a central role and requires special approaches.

In our article, two basic parts are contained: (a) the system evaluation process that is based on a hierarchical decision making procedure including our special attention to integration of local ordinal estimates into a global evaluation results; (b) the system improvement process that is considered from the viewpoint of operation management including the usage of support combinatorial models and a hierarchical decision making procedure. Our material is an addition to an existing set of corresponding approaches. The issues of the analysis and comparison of various methods for the above-mentioned two problems and selection of the best method for a certain applied design situation require special studies and are not examined here.

In the article, Hierarchical Morphological Multicriteria Design (HMMD) (Levin, 1998) is used as a basic approach to evaluate and to redesign the examined system. The approach realizes "partitioning/synthesis macroheuristic". Concurrently, other combinatorial models are briefly described: hierarchical integration of ordinal information and several combinatorial optimization problems for the system improvement/ redesign, e.g., knapsack problem, multiple choice problem, multicriteria ranking. Thus, our system evaluation part consists in hierarchical integration of expert judgment as ordinal estimates on the basis of the following: (i) integration tables (Glotov and Paveljev, 1984) and (ii) morphological approach (Levin, 1998; Levin, 2001). This is close to diagnosing some tree-structured systems (Stumptuer and Wotawa, 2001). The above-mentioned approaches lead to ordinal multi-state classification decisions which are used in many domains, for example: in control of financial risk (Agarwal et al., 2001); in medical diagnostics (Du Bois et al., 1989; Larichev et al., 1991); in quality analysis (Belkin and Levin, 1990); and in ordinal decision making/management (Cook and Kress, 1992).

It is reasonable to point out the basic kinds of the improvement/redesign problem (Levin, 1998):

Problem 1: Find the best improvement plan to reach a required level for the resultant system while taking into account the following: (i) results as a quality level for the resultant system and (ii) required resources (a set of admissible improvement actions).

Problem 2: Find the best level for the resultant system(s) while taking into account the following: (i) admissible limited resources (a set of admissible improvement actions) and (ii) some constraints for the improvement plan.

Here the improvement/redesign part is examined from the viewpoint of operations management including the following components: (a) a set of redesign operations; (b) some binary relations on the operations set above (e.g., equivalence, nonequivalence, complementarity, noncomplementarity, precedence); and (c) multiple criteria description 
of the operations. As a result, our improvement/redesign activity consists in a modular design of the system improvement plan on the basis of interconnected redesign operations. This approach is close to traditional planning in manufacturing.

Our system evaluation and improvement framework is oriented to and illustrated by a realistic numerical example for the evaluation and redesign of a two-floor building from the viewpoint of earthquake engineering.

\subsection{Evaluation and Improvement of Buildings}

The article addresses a framework of the system analysis, evaluation, and improvement/redesign for a certain applied domain: buildings from the viewpoint of earthquake engineering (Table 1) (Cheng and Wang, 1996; Hu et al., 1996; Jonsson, 2000; Kramer, 1995; Lagorio, 1990; Levin and Danieli, 2000; Marino, 1997; Naeim, 1989; Renhorn, 1999; Wakabayashi, 1984). In recent years, the significance of this application is increasing. Our paper does not address risk management (Hessami, 1999), postearthquake restoration and reconstruction (Kozin and Zhou, 1988), damage diagnosis of concrete structures using artificial intelligence techniques (e.g., neural networks) (Chao and Cheng, 1996; Tsa and Hsu, 2001), optimal and multiple criteria land use analysis and planning (Fischer et al., 1996; Yewlett, 2001), probabilistic approaches to seismic risk analysis (Budnitz et al., 1998; Lindell and Perry, 1997), simulation techniques (Fishman, 1996; Hon et al., 2000; Sobol, 1994), stochastic approaches to preventive maintenance (Gertsbakh, 2000; Usher et al., 1998), and economical issues of seismic design (Warshavsky et al., 1996). We consider a building as a composite (decomposable, modular) system. Some methodological issues for the design and redesign of buildings (mainly on

Table 1

Some bibliography sources in earthquake engineering and building design

\begin{tabular}{|c|c|}
\hline Topics & Sources \\
\hline 1. Design management and design framework & Austin et al., 1999; Baldwin et al., 1999 \\
\hline $\begin{array}{l}\text { 2. Earthquake engineering and seismic design } \\
\text { (general) }\end{array}$ & $\begin{array}{l}\text { Arnold and Reitherman, 1982; Hu et al., 1996; } \\
\text { Naeim, 1989; Wakabayashi, } 1996\end{array}$ \\
\hline 3. Description of earthquakes and regions & Flood et al., 1998; Kramer, 1995 \\
\hline 4. Modeling of earthquake situations & Flood et al., 1998 \\
\hline 5. Economical issues of seismic design & Warshavsky et al., 1996 \\
\hline $\begin{array}{l}\text { 6. Evaluation and assessment of buildings and } \\
\text { damage }\end{array}$ & $\begin{array}{l}\text { Budnitz et al., 1998; Chao and Cheng, 1996; Kanda } \\
\text { and Shah, 1997; Marino, 1997; Miyasato et al., } \\
\text { 1986; Neap, 2001; Renhorn, 1999; Soebarto and } \\
\text { Williamson, 2001; Tsa and Hsu, 2001 }\end{array}$ \\
\hline 7. Strengthening and improvement of buildings & $\begin{array}{l}\text { Bertero, 1992; Cheng and Wang, 1996; Davidovici, } \\
\text { 1993; Marino, } 1997\end{array}$ \\
\hline 8. Description of requirements to seismic design & Hu et al., 1996; Marino, 1997; Wakabayashi, 1984 \\
\hline 9. Seismic stability of auxiliary elements & Lagorio, 1990 \\
\hline 10. Configuration of buildings & $\begin{array}{l}\text { Arnold and Reitherman, 1982; Baglivo and Graber, } \\
\text { 1983; Park, } 2000\end{array}$ \\
\hline
\end{tabular}


the basis of special languages) have been described in (Austin et al., 1999; Baldwin et al., 1999; Hien et al., 2000).

Note some evaluation models for new products and systems are considered in (Fogliatto and Albin, 2001; Ozer, 1999; Soebarto and Williamson, 2001), special signal flow graphs are used for evaluation of design process alternatives in (Isaksson et al., 2000), fuzzy sets approach is applied for evaluation of design alternatives in (Knosala and Pedrycz, 1992).

Four basic redesign problems for buildings can be formulated on the basis of the following two dimensions:

(1) architectural requirements or requirements of earthquake engineering and

(2) redesign of a building project or redesign of an existing building.

Evaluation problems can be considered as follows:

(1) evaluation of a building or a project;

(2) evaluation of a real building after earthquake.

In the article, the following parts of the redesign scheme are proposed: (a) schemes for evaluation of buildings/projects; (b) a basic set of improvement/redsign actions (operations); (c) basic requirements for buildings; and (d) multicriteria description and binary relations (equivalence, complementarity, and precedence) for improvement actions; and (e) combinatorial problem formulations and solving schemes for the evaluation and redesign processes. A preliminary compressed version of our research was published in (Levin and Danieli, 2000).

Note our material leads to a hybrid approach that integrates decision making techniques and ordinal expert judgment as a special knowledge base. Some approaches to earthquake engineering on the basis of traditional artificial intelligence methods are described in (Miyasato et al., 1986). A numerical illustrative example illustrates the redesign framework for a building project.

In addition, it is reasonable to point out our material is an integrated effort of two specialists: Mark Sh. Levin (hierarchical schemes for the system analysis, evaluation and design/redesign; multicriteria decision making; combinatorial optimization: Sections 1.1, 2, 3.1, 3.2, 4.4) and Moshe A. Danieli (multi-year experience in the design and redesign of buildings from the viewpoint of earthquake engineering). As a result, Sections 1.2, 3.3, 3.4, 4.1, 4.2, 4.3 are joint ones.

\section{Two Hierarchical Approaches}

Hierarchical approaches for organization and management of engineering information on complex systems are basic ones (Kuppuraju et al., 1985; Levin, 1998; Wong and Sriram, 1993). In this section, we will describe two hierarchical methods: (a) HMMD for design, evaluation, and redesign of composite systems (Levin, 1998; Levin, 2001) and (b) simple hierarchical integration of ordinal information on the basis of tables (Glotov and Paveljev, 1984). 


\subsection{Morphological Design and Redesign (Partitioning/Synthesis Macroheuristic)}

In this paper, we examine composite (modular, decomposable) systems, consisting of components and their interconnection (Is) or compatibility. We use Hierarchical Morphological Multicriteria Design (HMMD) (Levin, 1998; Levin, 2001) that implements a partitioning/synthesis search strategy. HMMD extends well-known morphological analysis (Jones, 1981; Zwicky, 1969) by the use of ordinal quality estimates for design alternatives and their compatibility.

There exist two main problems: 1) design of combinatorial search space and 2) design of a search strategy at the space. Fig. 1 illustrates the partitioning/synthesis strategy on the basis of the following stages: (a) partitioning the initial search space into subspaces; (b) search for the best local decision for each subspace; and (c) combination (composition, synthesis) of the local decisions into the global resultant decision.

Basic assumptions of HMMD are the following: (a) a considered system has a treelike structure; (b) a system excellence is a composite estimate which integrates components (subsystems, parts) qualities and qualities of Is (compatibility) among subsystems; (c) monotone criteria for the system and its components are used; (d) quality of system components and Is are evaluated on the basis of coordinated ordinal scales. The following designations are used: (1) design alternatives (DA's) for leaf nodes of the model; (2) priorities of DA's ( $r=1, \ldots, k ; 1$ corresponds to the best one); (3) ordinal compatibility (Is) for each pair of DA's ( $w=0, \ldots, l, l$ corresponds to the best one).

A basic version of HMMD involves the following phases:

1) design of the tree-like system model;

2) generation of DA's for leaf nodes of the model;

3) hierarchical selection and composing of DA's into composite DA's for the corresponding higher level of the system hierarchy;

4) analysis and improvement of composite DA's (decisions).

The synthesis problem for composite DA's is the following. Let $S$ be a composite system consisting of $m$ parts (components): $P(1), \ldots, P(i), \ldots, P(m)$. A set of design alternatives exists for each system part above. The problem is:

Find a composite design alternative $S=S(1) \star \ldots \star S(i) \star \ldots \star S(m)$ of DA's (one representative design alternative $S(i)$ for each system component/part $P(i)$, $i=1, \ldots, m)$ with non-zero Is between design alternatives.
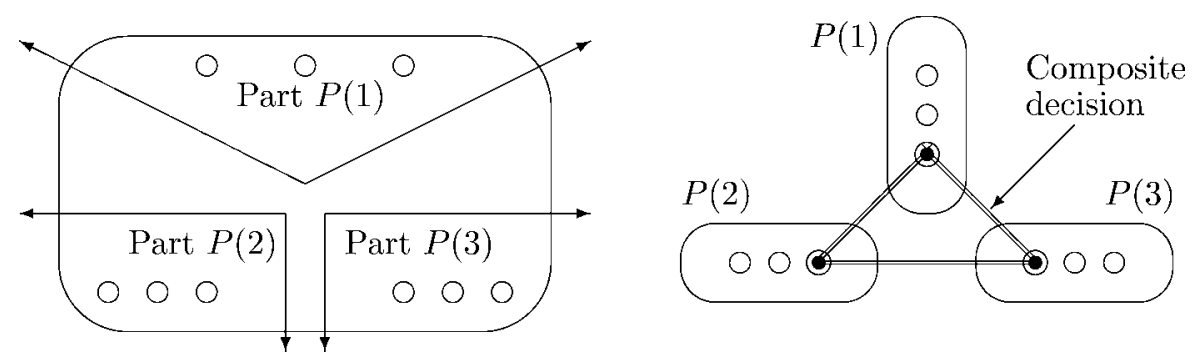

Fig. 1. Partitioning/synthesis strategy. 
A discrete space of the system excellence on the basis of the following vector is used: $N(S)=(w(S) ; n(S))$, where $w(S)$ is the minimum of pairwise compatibility between DA's which correspond to different system components (i.e., $\forall P_{j_{1}}$ and $P_{j_{2}}, 1 \leqslant j_{1} \neq$ $\left.j_{2} \leqslant m\right)$ in $S, n(S)=\left(n_{1}, \ldots, n_{r}, \ldots n_{k}\right)$, where $n_{r}$ is the number of DA's of the $r$ th quality in $S$. As a result, we search for composite decisions which are nondominated by $N(S)$. Thus, the following layers of system excellence can be considered: (i) ideal point; (ii) Pareto-effective points; (iii) a neighborhood of Pareto-effective DA's (e.g., a composite decision of this set can be transformed into a Pareto-effective point on the basis of an improvement action(s)).

Fig. 2 illustrates decomposable system $S=X \star Y \star Z$. Here examples of the composite decisions are: $S_{1}=X_{1} \star Y_{4} \star Z_{3} ; S_{2}=X_{1} \star Y_{1} \star Z_{2}$; and $S_{3}=X_{2} \star Y_{5} \star Z_{2}$. For composite decision in Fig. 2, we get $N\left(S_{1}\right)=(1 ; 0,2,1), N\left(S_{2}\right)=(3 ; 1,1,1)$, and $N\left(S_{3}\right)=$ $(2 ; 2,0,1)$. Thus $N\left(S_{2}\right)$ and $N\left(S_{3}\right)$ are Pareto-effective points and $N\left(S_{2}\right) \succ N\left(S_{1}\right)$, $N\left(S_{3}\right) \succ N\left(S_{1}\right)$. Fig. 3 depicts an example of the discrete space of system quality for a fixed level of compatibility (for $n(S)$ ). Fig. 4 illustrates the integrated discrete space of system quality (for $N(S)$ ) and examples of decisions. This space consists of three ordered lattices each of them corresponds to the lattice from Fig. 3. In general case, a lattice that represents $n(S)=\left(n_{1}, \ldots, n_{r}, \ldots, n_{k}\right)$ has a "triangle" form.

Fig. 5 illustrates decomposable system $S=A \star B \star C$ and its redesign (up-grade) into $S=A \star B \star D$ : change of system components (deletion is denoted by $X^{-}$and addition is denoted by $\left.X^{+}\right)$and change of system model $(C \rightarrow D)$, for example: $S^{\prime}=$ $A_{2} \star B_{1} \star C_{1} \Rightarrow S^{\prime \prime}=A_{3} \star B_{3} \star D_{2}$.

The following kinds of elements (DA's, Is) with respect to solution $S$ can be examined: $S$-improving, $S$-neutral, and $S$-aggravating ones by vector $N$; where $S$-aggravating elements are examined as bottlenecks.

Fig. 6 illustrates an improvement process for a composite system. Here we examine the following layers of decisions: (1) an initial point; (2) points that are close to the Pareto-effective layer; (3) the Pareto-effective decisions; (4) points that are a little better than the Pareto-effective decisions; (5) points that are close to the ideal decision; and (6) the ideal decision. Thus it is reasonable to improve step-by-step an initial decision.
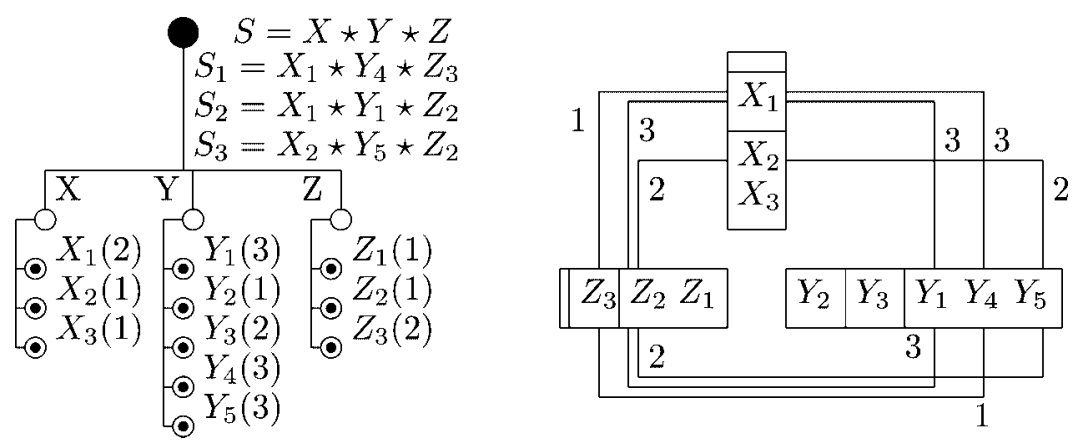

Fig. 2. Example of composition problem (priorities of DA's are shown in brackets). 


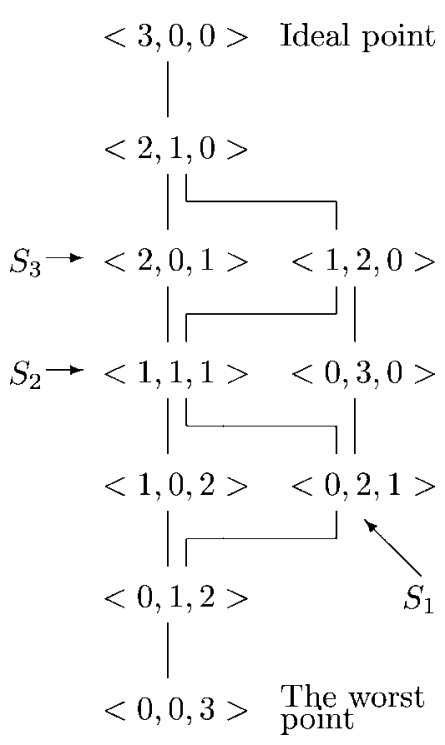

Fig. 3. Position (histogram) presentation of the lattice of system quality for $N=\left(w ; n_{1}, n_{2}, n_{3}\right)$, $w=$ const, $m=3, l=3$.

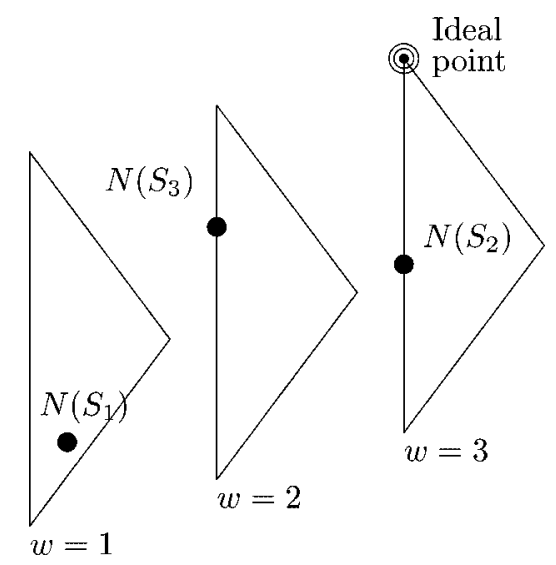

Fig. 4. Discrete space of system excellence for $N(S)$.

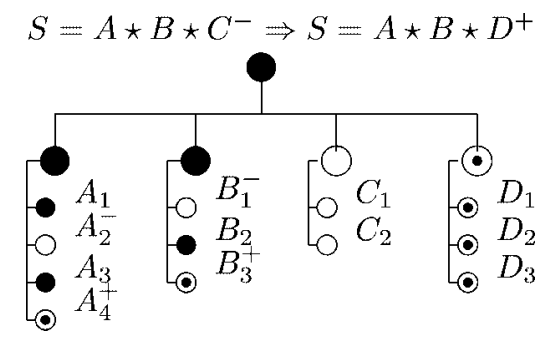

Fig. 5. Example of redesigned system.

In Fig. 6, the following points and trajectories are depicted: (a) points: (i) initial point $S_{o}$; (ii) intermediate points of improvements $S_{o 1}$ and $S_{o 2}$; (iii) four Pareto-effective points; (iv) additional intermediate points $S_{1}^{i}$ and $S_{2}^{i}$; (v) resultant points $S_{1}^{*}$ and $S_{2}^{*}$; and (vi) the ideal point $I$; (b) series trajectories of improvements: $\alpha=<S_{o}, S_{o 1}, S_{1}^{i}, S_{1}^{*}>$ and $\beta=<S_{o}, S_{o 2}, S_{2}^{i}, S_{2}^{*}>$.

Note extended versions of discrete spaces for system excellence are proposed in (Levin, 2001). Now let us list some support procedures as follows:

1) mulricriteria ranking to get the above-mentioned ordinal priorities of DA's or ordinal estimates of Is (Buede, 1992);

2) morphological clique problem to find composite DA's (Levin, 1998);

3) multicriteria analysis (ranking) of composite DA's (Levin, 1998);

4) generation of improvement actions, for example, on the basis of domain expert judgment; 


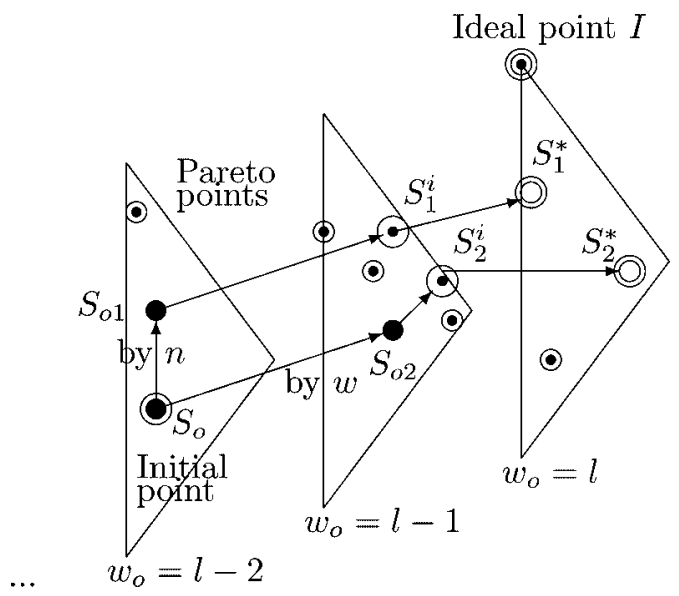

Fig. 6. Excellence lattice, improvements $(\rightarrow)$.

5) design of series-parallel schedule for improvement actions (Blazewicz et al., 1994);

6) searching for the best trajectory in an operational network on the basis of the following: (i) operations management (Singhal and Katz, 1990), (ii) network methods and techniques, e.g., dynamic programming (Garey and Johnson, 1979), hierarchical task-network planning (Erol et al., 1996), scheduling (Blazewicz et al., 1994; Garey and Johnson, 1979).

\subsection{Hierarchical Integration of Ordinal Information}

Here we briefly describe a hierarchical procedure for integration of ordinal estimates that was proposed in (Glotov and Paveljev, 1984). In this case, parts/components of a system are evaluated upon ordinal scales and integration of the scales for composite system parts/components is based on integration tables that are obtained from expert judgment. The integration tables correspond to monotone functions of algebraic logic (or multiplevalued logic) which have been studied in mathematical logic (Serzantov, 1984) and in decision making procedures, e.g., in DSS COMBI (Levin, 1998). Note close techniques are applied in technical diagnosis for electronic systems. A numerical example is presented in Fig. 7 (system structure and ordinal scales of quality for the system and each its component) and in Fig. 8 (a process of information integration on the basis of integration tables). For example, let us consider some estimates for the system components $B, C$, and $D$ as follows: $3,2,1$ accordantly. On the basis of integration table for $B \& C$ we get an estimate for $A: 3$; and on the basis of integration table for $A \& D$ we get an estimate for $S: 2$. 


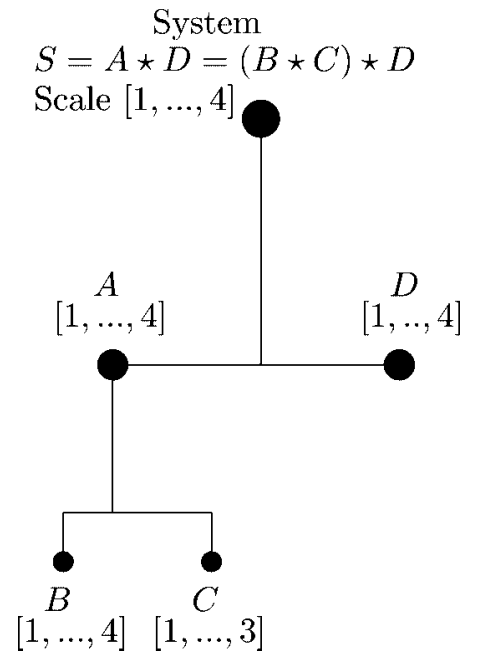

Fig. 7. System structure.

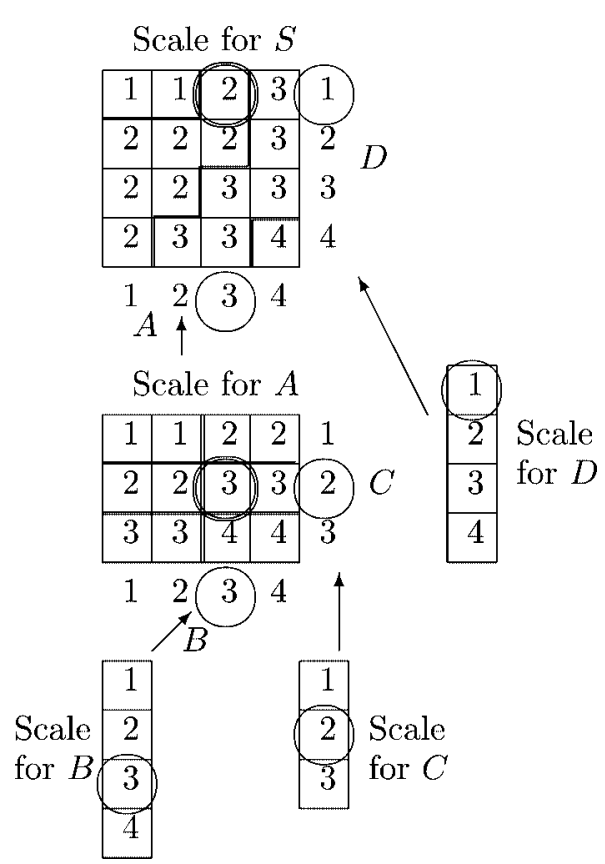

Fig. 8. Integration of ordinal scales.

\section{Scheme of Improvement/Redesign}

\subsection{Framework}

Our framework for a system (building) is based on hierarchical morphological multicriteria design HMMD from (Levin, 1998) and consists of the following:

I. Design of hierarchical model and description for a system.

1.1. Design of hierarchical model for a system.

1.2. Design of multicriteria (multifactor) hierarchical description of the model nodes (building parts, components) including ordinal scales for each criterion.

\section{Evaluation.}

2.1. Assessment of the system parts/components upon criteria.

2.2. Step-by-step aggregation of information to get an estimate for a higher level of the model hierarchy (on the basis of multicriteria decision making techniques from (Glotov and Paveljev, 1984; Levin, 1998).

III. Analysis of the building and revelation of bottlenecks (Levin, 1998).

3.1. Analysis of the resultant integrated estimate for the system, analysis of system parts/components and their interconnection.

3.2. Revelation of the bottlenecks as some weak building parts/components or their interconnection (if it is necessary). 


\section{Design of improvement process for the system (Levin, 1998):}

4.1. Generation/selection of a set of some possible improvement actions.

4.2. Selection/composition of the best subset of the improvement actions while taking into account certain design and technological requirements (situations).

4.3. Scheduling of the improvement actions above.

The above-mentioned framework is described and realized for building in next sections from the generalized viewpoint and as a numerical example:

(a) hierarchical system model for building, criteria, and the ordinal scales for evaluation of the building parts in Section 3.2;

(b) evaluation examples: (i) on the basis of integration tables (Section 4.1), (ii) on the basis of hierarchical morphological approach (Section 4.2);

(c) analysis of the system and redesign: (i) generalized basic set of improvement actions for building (Section 3.4), (ii) a certain set of the redesign operations with binary relations, criteria, estimates, and ranking (Section 4.3); (iii) models for the selection and scheduling of the redesign operations (models in Section 3.2 and an improvement process on the basis of these models in Section 4.4).

\subsection{Structure of Building, Criteria, and Scales}

In this section, the following is examined: (i) tree-like model for a building; (ii) criteria for the improvement/redesign of building; and (iii) weights and scales for the criteria. Note a basic overview of critical problems and issues associated with hierarchical modeling of large scale systems is contained in (Haimes, 1982). The algorithms for the design of hierarchical models for engineering systems are described in (Papalambros and Michelena, 1997).

In our paper, the weights of the criteria are oriented to a certain redesign problem. Here, the problem of project redesigning from the viewpoint of earthquake engineering is considered. In the example, it is assumed a certain earthquake situation (8-mark estimate, scale of seismic intensivity MSK-64). Other redesign problems can be studied on the basis of other improvement (redesign) actions and a weight system for the criteria. Note classification of building types and main classes of structural failures and damages are considered in (Kanda and Shah, 1997).

Our basic hierarchical structure of a building is the following:

\section{Building $S$.}

1.1. Foundation $A$.

1.2. Basic structure $B$.

1.2.1. Bearing structures $D$ :

1.2.1.1. Frame $E$,

1.2.1.2. Rigidity core $G$,

1.2.1.3. Staircase $H$. 
1.2.2. Nonbearing structures $F$ :

1.2.2.1. Filler walls $I$,

1.2.2.2. Partitioning walls $J$.

\subsection{Floors $C$.}

Note that configuration of buildings (e.g., symmetry) plays a crucial role (Arnold and Reitherman, 1982; Baglivo and Graver, 1983; Park, 2000; Shubnikov and Koptsik, 1974). The following scale can be used for configuration: 1 corresponds to $\mathrm{bad}, 2$ corresponds to good, and 3 corresponds to excellent (symmetrical, etc.). In our opinion, the good configuration deals to decreasing of building damage (i.e., decreasing an damage estimate by one level).

Our hierarchical criteria set is based on the following two parts:

1. Characteristics of the building including the following main parameters: (a) volume-plan design decisions (regularity of a building system, symmetry, location of rigidity building mass or mass of rigidity core for building, dimensions); (b) engineeringgeological situation, etc.

2. A hierarchical criteria set for the evaluation of a certain building at a certain situation (on the basis of extremal influence): (a) volume; (b) type (vertical, horizontal); (c) correspondence between direction of influence and plan of building; and (d) dynamical character of oscillations.

The following basic coordinated ordinal scales for the building parts/components is proposed $([1, \ldots, 5])$ : global destruction $(1)$; local destruction $(2)$; chinks $(3)$; small chinks (hair-like) (4); and without damage (5). For each building part/components we use a special ordinal scale that is a subscale of the scale above (Table 2). Note ordinal multi-level/multi-state classification decisions are used in many engineering domains, e.g., a small survey is contained in (Levin, 1998). An example of the ordinal four-state

Table 2

Ordinal scale for evaluation of building components

\begin{tabular}{|c|c|c|c|c|c|}
\hline \multirow{2}{*}{$\begin{array}{l}\text { Parts of } \\
\text { building }\end{array}$} & \multicolumn{5}{|c|}{ Scales } \\
\hline & $\begin{array}{l}\text { destruction } \\
\text { (global) (1) }\end{array}$ & $\begin{array}{c}\text { destruction } \\
(\text { local })(2)\end{array}$ & chinks (3) & $\begin{array}{c}\text { small } \\
\text { chinks (4) }\end{array}$ & $\begin{array}{c}\text { without } \\
\text { damage }(5)\end{array}$ \\
\hline 1 & & $*$ & $*$ & $*$ & $*$ \\
\hline 1.1 & & & $*$ & $*$ & $*$ \\
\hline 1.2 & & $*$ & $*$ & $*$ & $*$ \\
\hline 1.2 .1 & & & $*$ & $*$ & $*$ \\
\hline 1.2 .1 .1 & & & $*$ & $*$ & $*$ \\
\hline 1.2 .1 .2 & & & & $*$ & $*$ \\
\hline 1.2.1.3 & & & $*$ & $*$ & $*$ \\
\hline 1.2 .2 & & $*$ & $*$ & $*$ & $*$ \\
\hline 1.2 .2 .1 & & $*$ & $*$ & $*$ & $*$ \\
\hline 1.2 .2 .2 & & $*$ & $*$ & $*$ & * \\
\hline 1.3 & & $*$ & $*$ & $*$ & $*$ \\
\hline
\end{tabular}


classification to classify firms is the following: healthy, divided reduction, debt default, and bankrupt (Agarwal et al., 2001).

Thus in our case of building, we use, for example, the following ordinal scales (Table 2): scale $[3,4,5]$ for foundation $A(\mathbf{1 . 1})$; scale $[4,5]$ for rigidity core $G$ (1.2.1.2); scale $[2,3,4,5]$ for floors $C(\mathbf{1 . 3})$;

\subsection{Models and Procedures}

In this paper, two described hierarchical approaches, i.e., hierarchical morphological design (and corresponding morphological clique problem) and hierarchical integration of ordinal information by tables, are oriented to the system evaluation. At the same time, hierarchical morphological design is useful for revelation of a set of system bottlenecks which are a basis for the improvement stage (e.g., a set of possible improvement actions). On the other hand, this generation of possible improvement actions (operations) can be based on expert judgment. Further, it is necessary to select the more important improvement operations and to design a plan (a schedule) for the selected operations. At this stage, the list of basic support procedures is the following:

1. Selection of items (e.g., design/redesign alternative operations).

2. Selection of items while taking into account some resource constraints.

3. Definition of parameter values for items.

4. Integration/synthesis of items into a composite system (subsystem).

5. Ranking of items while taking into account their attributes.

6. Ordering/scheduling the items.

Let us briefly point out some support models for the above-mentioned procedures as follows:

1. Knapsack problem for selection of improvement actions while taking into account their "utility" and some resource constraints. The basic problem is (Garey and Johnson, 1979; Martello and Toth, 1990):

$$
\max \sum_{i=1}^{m} c_{i} x_{i}, \quad \text { s.t. } \quad \sum_{i=1}^{m} a_{i} x_{i} \leqslant b \quad x_{i}=0 \cup 1, \quad i=1, \ldots, m,
$$

and additional resource constraints $\sum_{i=1}^{m} a_{i, k} x_{i} \leqslant b_{k} ; k=1, \ldots, l$; where $x_{i}=1$ if item $i$ is selected, for $i$ th item $c_{i}$ is a value ("utility"), and $a_{i}$ is a weight. Often nonnegative coefficients are assumed.

2. Multiple-choice problem for selection of improvement actions while taking into account their "utility" and some resource constraints. In this case, the actions are divided into groups and we select actions from each group. The problem is (Martello and Toth, 1990):

$$
\begin{aligned}
& \max \sum_{j=1}^{m} \sum_{i=1}^{q_{j}} c_{i, j} x_{i, j} \quad \text { s.t. } \quad \sum_{j=1}^{m} \sum_{i=1}^{q_{j}} a_{i, j} x_{i, j} \leqslant b \\
& \sum_{i=1}^{q_{j}} x_{i, j} \leqslant 1 ; \quad j=1, \ldots, m, \quad x_{i, j}=0 \cup 1 ; i=1, \ldots, q_{j} ; j=1, \ldots, m .
\end{aligned}
$$


3. Multiple criteria ranking for ordering the actions while taking into account their estimates upon criteria. The problem is the following. Let $V=\{1, \ldots, i, \ldots, p\}$ be a set of items which are evaluated upon criteria $K=1, \ldots, j, \ldots, d$ and $z_{i, j}$ is an estimate (quantitative, ordinal) of item $i$ on criterion $j$. The matrix $\left\{z_{i, j}\right\}$ can be mapped into a partial order on $V$. The following partition as linear ordered subsets of $V$ is searching for:

$$
\begin{aligned}
& V=\cup_{k=1}^{m} V(k), \quad\left|V\left(k_{1}\right) \& V\left(k_{2}\right)\right|=0 \text { if } k_{1} \neq k_{2}, \\
& i_{2} \preceq i_{1} \forall i_{1} \in V\left(k_{1}\right), \quad \forall i_{2} \in V\left(k_{2}\right), \quad k_{1} \leqslant k_{2} .
\end{aligned}
$$

Set $V(k)$ is called layer $k$, and each item $i \in V$ get priority $r_{i}$ that equals the number of the corresponding layer.

4. The morphological clique problem was briefly described in Section 2.1 (Levin, 1998).

5. Scheduling the redesign actions can be based on well-known scheduling problems. Formulations of scheduling problems are described in (Blazewiz et al., 1994).

6. For some complicated situations, it may be reasonable to examine mixed integer non-linear programming models (Floudas, 1995; Grossmann, 1990). Here our efforts are oriented not only to select the best operations while taking into account their "utilities" and resource constraints but to define some continuous parameter values for the operations too.

The usage of the first four pointed out support models will be illustrated in Subsection 4.4.

\subsection{Basic Set of Improvement Actions}

Upgrading issues for structures/buildings including strengthening of an existing building have been considered by many authors (Bertero, 1992; Cheng and Wang, 1996; Davidovici, 1993; Marino, 1997; Tudor and Ciuhandu, 1992). Here the following basic set of improvement actions (redesign operations) for buildings from the viewpoint of earthquake engineering is considered:

\section{A. Internal actions}

1. Decreasing the weight: 1.1. insulating materials (e.g., thermal, acoustic, etc.); 1.2. bearing walls (a frame); 1.3. non-bearing walls; and 1.4. floors.

2. Modification of static scheme: 2.1. design of rigidity core and 2.2. increasing a static indetermination of structure (2.2.1 redesign of hinge joints into rigid ones; 2.2.2. design of additional supporters; 2.2.3. design of additional joints; and 2.2.4. design of additional connectors).

3. Strengthening some structural elements and connectors (design of additional elements): 3.1. beams; 3.2. columns; 3.3. walls; 3.4. floor slabs; 3.5. partition walls; 3.6. connectors; 3.7. floors (dome, vanet, etc.); and 3.8. foundation.

4. Additional structural systems and elements: 4.1. flexible antiseismic girt; 4.2. rigid antiseismic girt (metal, concrete); 4.3. metal rigidity frame; 4.4. concrete rigidity frame; and 4.5. shear wall. 


\section{B. External decisions}

In addition, it is reasonable to define the following three kinds of binary relations on the improvement actions set: (1) equivalence of actions $R^{e}$; (2) complementarity $R^{c}$; and (3) precedence $R^{p}$. Further, the above-mentioned generalized improvement actions are transformed into certain 11 redesign operations in Section 4.3.

\section{Numerical Examples}

In this section an illustrative example for the improvement (redesign) of a building is described. We examine (from the viewpoint of earthquake engineering) a simple two-floor building (Fig. 9) that is widely used in many countries (Greece, Turkey, Israel, etc.). The evaluation examples are contained in Sections 4.1 (integration tables) and 4.2 (morphological hierarchical approach). Further, Section 4.3 contains 11 redesign operations and their description, Section 4.4 depicts an improvement process with a comparison of four support models. Evidently, our example is based on our expert judgment (e.g., integration tables, estimates in hierarchical morphological approach, redesign operations and their description). Thus the example and its parts can be used as an illustration and as a basis of other applications.

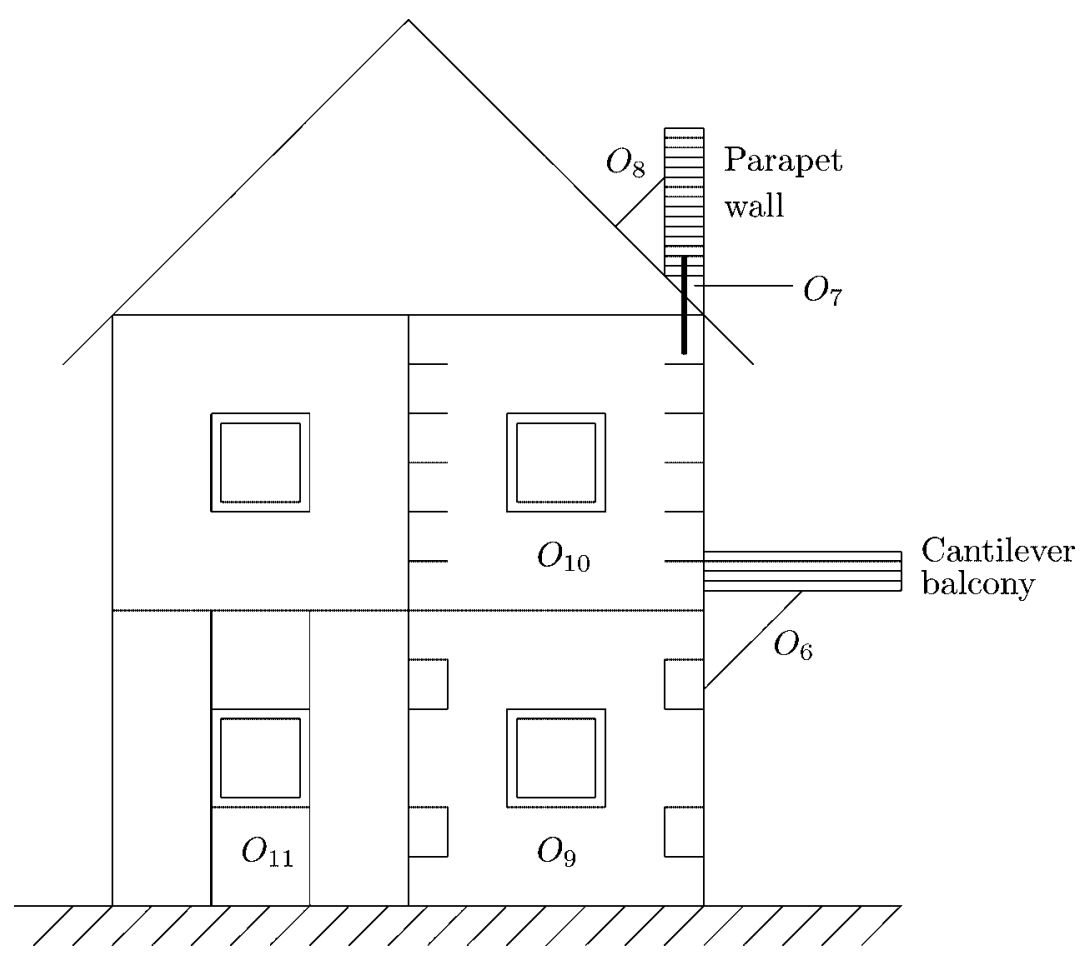

Fig. 9. Draft of a building example and redesign operations. 


\subsection{Evaluation Example: Integration Tables}

Here an evaluation example for a building after earthquake is examined. Integration tables are presented in Figs. 10, 11, and 12 (“-” corresponds to impossible situations). As a

Nonbearing structure $\mathbf{1 . 2 . 2}$

$[2, \ldots, 5]$

\begin{tabular}{|c|c|c|c|c|}
\hline 2 & 2 & - & - & 2 \\
\hline 3 & 3 & - & - & 3 Filler \\
\hline 3 & 3 & 4 & - & 4 walls \\
\hline- & 4 & 4 & 5 & $5^{1.2 .2 .2}$ \\
\hline & $\begin{array}{l}3 \\
\text { tit } \\
\end{array}$ & $\begin{array}{c}4 \\
\text { oni } \\
2 .\end{array}$ & & \\
\hline
\end{tabular}

Basic structure $\mathbf{1 . 2}$

$[2, \ldots, 5]$

\begin{tabular}{|c|c|c|c|c|}
\hline 2 & 3 & - & - & \multirow{3}{*}{$\begin{array}{l}3 \text { Bearing } \\
4 \text { structures } \\
5\end{array}$} \\
\hline 3 & 4 & 4 & - & \\
\hline- & 4 & 5 & 5 & \\
\hline 2 & 3 & $\begin{array}{c}4 \\
\mathrm{ng}\end{array}$ & $\begin{array}{c}5 \\
\text { tru }\end{array}$ & \\
\hline
\end{tabular}

Fig. 10. Integration tables for system and parts $\mathbf{1 . 2}$ and $\mathbf{1 . 2 . 2}$.

\begin{tabular}{|c|c|c|c|}
\hline $1.1[3 \ldots 5]$ & $1.2[4 \ldots .5]$ & $1.3[3 \ldots 5]$ & 1 \\
\hline 3 & 2 & 2 & 2 \\
\hline 3 & 2 & 3 & - \\
\hline 3 & 2 & 4 & - \\
\hline 3 & 2 & 5 & - \\
\hline 3 & 3 & 2 & 2 \\
\hline 3 & 3 & 3 & 3 \\
\hline 3 & 3 & 4 & 3 \\
\hline 3 & 3 & 5 & - \\
\hline 3 & 4 & 2 & - \\
\hline 3 & 4 & 3 & - \\
\hline 3 & 4 & 4 & - \\
\hline 3 & 4 & 5 & - \\
\hline 3 & 5 & 2 & - \\
\hline 3 & 5 & 3 & - \\
\hline 3 & 5 & 4 & - \\
\hline 3 & 5 & 5 & - \\
\hline 5 & 2 & 2 & 2 \\
\hline 5 & 2 & 3 & - \\
\hline 5 & 2 & 4 & - \\
\hline 5 & 2 & 5 & - \\
\hline 5 & 3 & 2 & - \\
\hline 5 & 3 & 3 & - \\
\hline 5 & 3 & 4 & 3 \\
\hline 5 & 3 & 5 & 3 \\
\hline 5 & 4 & 2 & - \\
\hline 5 & 4 & 3 & - \\
\hline 5 & 4 & 4 & 4 \\
\hline 5 & 4 & 5 & 4 \\
\hline 5 & 5 & 2 & - \\
\hline 5 & 5 & 3 & - \\
\hline 5 & 5 & 4 & - \\
\hline 5 & 5 & 5 & 5 \\
\hline
\end{tabular}

\begin{tabular}{|c|c|c|c|}
\hline $1.1[3 \ldots 5]$ & $1.2[4 \ldots 5]$ & $1.3[3 \ldots 5]$ & $\mathbf{1}$ \\
\hline 4 & 2 & 2 & 2 \\
4 & 2 & 3 & - \\
4 & 2 & 4 & - \\
4 & 2 & 5 & - \\
4 & 3 & 2 & - \\
4 & 3 & 3 & 3 \\
4 & 3 & 4 & 3 \\
4 & 3 & 5 & - \\
4 & 4 & 2 & - \\
4 & 4 & 3 & - \\
4 & 4 & 4 & 4 \\
4 & 4 & 5 & 4 \\
4 & 5 & 2 & - \\
4 & 5 & 3 & - \\
4 & 5 & 4 & - \\
4 & 5 & 5 & - \\
\hline
\end{tabular}

Fig. 11. Integration tables for building $\mathbf{1}([2, \ldots, 5])$. 


\begin{tabular}{|c|c|c|c|}
\hline $\begin{array}{c}1.2 .1 .1 \\
{[3 \ldots . .5]}\end{array}$ & $\begin{array}{c}1.2 .1 .2 \\
{[4 \ldots 5]}\end{array}$ & $\begin{array}{c}1.2 .1 .3 \\
{[3 \ldots .5]}\end{array}$ & $\mathbf{1 . 2 . 1}$ \\
\hline 3 & 4 & 3 & 3 \\
3 & 4 & 4 & 3 \\
3 & 4 & 5 & - \\
3 & 5 & 3 & 3 \\
3 & 5 & 4 & 3 \\
3 & 5 & 5 & - \\
5 & 4 & 3 & 3 \\
5 & 4 & 4 & 4 \\
5 & 4 & 5 & 4 \\
5 & 5 & 3 & 4 \\
5 & 5 & 4 & 4 \\
5 & 5 & 5 & 5 \\
\hline
\end{tabular}

\begin{tabular}{|c|c|c|c|}
\hline $\begin{array}{c}1.2 .1 .1 \\
{[3 \ldots . .5]}\end{array}$ & $\begin{array}{c}1.2 .1 .2 \\
{[4 \ldots 5]}\end{array}$ & $\begin{array}{c}1.2 .1 .3 \\
{[3 \ldots .5]}\end{array}$ & $\mathbf{1 . 2 . 1}$ \\
\hline 4 & 4 & 3 & 3 \\
4 & 4 & 4 & 4 \\
4 & 4 & 5 & - \\
4 & 5 & 3 & 3 \\
4 & 5 & 4 & 4 \\
4 & 5 & 5 & 4 \\
\hline
\end{tabular}

Fig. 12. Integration tables for bearing structures $\mathbf{1 . 2 . 1}([3, \ldots, 5])$.

result, now it is possible to evaluate a building after earthquake:

Example 1. Local expert evaluation of a building: 1.1: 4, 1.2.1.1: 3, 1.2.1.2: 4, 1.2.1.3: 3, 1.2.2.1: 2, 1.2.2.2: 2 , and 1.3: 2 ; resultant estimate for building 1 equals 2 .

Example 2. Local expert evaluation of a building: 1.1: 5, 1.2.1.1: 4, 1.2.1.2: 5, 1.2.1.3: 4, 1.2.2.1: 4, 1.2.2.2: 3 , and 1.3: 4; resultant estimate for building 1 equals 4 .

Example 3. Local expert evaluation of a building: 1.1: 5, 1.2.1.1: 3, 1.2.1.2: 5 , 1.2.1.3: 4, 1.2.2.1: 3, 1.2.2.2: 3 , and 1.3: 4; resultant estimate for building 1 equals 3 .

Example 4. Local expert evaluation of a building: 1.1: 5, 1.2.1.1: 5, 1.2.1.2: 5 , 1.2.1.3: $5,1.2 .2 .1: 4,1.2 .2 .2: 4$, and 1.3: 5 ; resultant estimate for building 1 equals 5 .

\subsection{Evaluation Example: Morphological Design}

In this section, an evaluation example for a building project is described. First, let us generate design alternatives (DA's) for building components as follows (priorities from the viewpoint of earthquake engineering are shown in brackets):

Foundation: $A_{1}$, strip foundation (2), $A_{2}$, bedplate foundation (1), $A_{3}$, foundation consisting of isolated parts (2).

Frame: $E_{1}$, monolith frame (1), $E_{2}$, precast frame (2).

Rigidity core: $G_{1}$, monolith rigid core (1), $G_{2}$, precast rigid core (2).

Staircase: $H_{1}$, monolith staircase (1), $H_{2}$, precast staircase (2), $H_{3}$, composite staircase consisting of precast and monolith elements (3).

Filler walls: $I_{1}$, small elements (2), $I_{2}$, curtain panel walls (2), $I_{3}$, precast enclosure panel walls (1), $I_{4}$, frame walls (1).

Partitioning walls: $J_{1}$, precast panel walls (1), $J_{2}$, small elements (3), $J_{3}$, frame walls (2).

Floors: $C_{1}$, monolith slabs (1), $C_{2}$, composite slabs (3), $C_{3}$, precast slabs (3).

Note the example is compressed one. It is reasonable to use many criteria to evaluate the above-mentioned DA's (see Section 4.3).

Here the following composite DA's are considered:

$D_{1}=E_{1} \star G_{1} \star H_{1}, N\left(D_{1}\right)=(3 ; 3,0,0) ; D_{2}=E_{1} \star G_{1} \star H_{2}, N\left(D_{2}\right)=(1 ; 2,1,0) ;$ 


$$
\begin{aligned}
& D_{3}=E_{1} \star G_{1} \star H_{3}, N\left(D_{3}\right)=(1 ; 2,0,1) ; D_{4}=E_{1} \star G_{2} \star H_{1}, N\left(D_{4}\right)=(2 ; 2,1,0) ; \\
& D_{5}=E_{1} \star G_{2} \star H_{2}, N\left(D_{5}\right)=(1 ; 1,2,0) ; D_{6}=E_{1} \star G_{2} \star H_{3}, N\left(D_{6}\right)=(1 ; 1,1,1) ; \\
& D_{7}=E_{2} \star G_{1} \star H_{1}, N\left(D_{7}\right)=(2 ; 2,1,0) ; D_{8}=E_{2} \star G_{1} \star H_{2}, N\left(D_{8}\right)=(1 ; 1,2,0) ; \\
& D_{9}=E_{2} \star G_{1} \star H_{3}, N\left(D_{9}\right)=(1 ; 1,1,1) ; D_{10}=E_{2} \star G_{2} \star H_{1}, N\left(D_{10}\right)=(1 ; 1,2,0) ; \\
& D_{11}=E_{2} \star G_{2} \star H_{2}, N\left(D_{11}\right)=(1 ; 3,0,0) ; D_{12}=E_{2} \star G_{2} \star H_{3}, N\left(D_{12}\right)=
\end{aligned}
$$

Thus, we can select for our next examination the following four best and good DA's for $D$ (Fig. 13): (a) $D_{1}$ (ideal solutions, priority equals 1 ); (b) $D_{4}, D_{7}$, and $D_{11}$ (some Pareto-effective solutions without taking into account $D_{1}$, priority equals 2).

Analogically, we can select for our next examination the following four best and good DA's for $F$ (Fig. 14): (a) $F_{7}, F_{10}$ (ideal solutions, priority equals 1 ); (b) $F_{9}, F_{12}$ (good solutions, priority equals 2 ).

Generally, we can assume that the priority of other DA's for $D$ and $F$ will equal 3.

Now let us consider 12 composite DA's for $B$ on the basis of the above-mentioned selected four DA's for $D$ and for $F$ (accordingly):

$$
\begin{array}{llll}
B_{1}=D_{1} \star F_{7}, & N\left(B_{1}\right)=(2 ; 2,0,0) ; & B_{2}=D_{1} \star F_{9}, & N\left(B_{2}\right)=(2 ; 1,1,0) ; \\
B_{3}=D_{1} \star F_{10}, & N\left(B_{3}\right)=(2 ; 2,0,0) ; & B_{4}=D_{1} \star F_{12}, & N\left(B_{4}\right)=(3 ; 1,1,0) ; \\
B_{5}=D_{4} \star F_{7}, & N\left(B_{5}\right)=(2 ; 0,1,1) ; & B_{6}=D_{4} \star F_{9}, & N\left(B_{6}\right)=(2 ; 0,2,0) ; \\
B_{7}=D_{4} \star F_{10}, & N\left(B_{7}\right)=(2 ; 1,1,0) ; & B_{8}=D_{4} \star F_{12}, & N\left(B_{8}\right)=(2 ; 0,2,0) ; \\
B_{9}=D_{7} \star F_{7}, & N\left(B_{9}\right)=(2 ; 0,1,1) ; & B_{10}=D_{7} \star F_{9}, & N\left(B_{10}\right)=(2 ; 0,2,0) ; \\
B_{11}=D_{7} \star F_{10}, & N\left(B_{11}\right)=(2 ; 1,1,0) ; & B_{12}=D_{7} \star F_{12}, & N\left(B_{12}\right)=(2 ; 0,2,0) ; \\
B_{13}=D_{11} \star F_{7}, & N\left(B_{13}\right)=(3 ; 1,1,0) ; & B_{14}=D_{11} \star F_{9}, & N\left(B_{14}\right)=(2 ; 0,2,0) ; \\
B_{15}=D_{11} \star F_{10}, & N\left(B_{15}\right)=(2 ; 1,1,0) ; & B_{16}=D_{11} \star F_{12}, & N\left(B_{16}\right)=(2 ; 0,2,0) .
\end{array}
$$

As a result, we have to select the following DA's for $B$ (Fig. 15):

(a) $N=(3 ; 1,1,0): B_{4}=D_{1} \star F_{12}, B_{13}=D_{11} \star F_{7}$;

(b) $N=(2 ; 2,1,0): B_{1}=D_{1} \star F_{7}, B_{3}=D_{1} \star F_{10}$.

Evidently, these DA's have a priority that equals 2 (priority for all others equals 3 ).

Finally, we get the following composite DA's for our system (building, Fig. 16):

(a) $N=(3 ; 2,1,0): S_{1}=A_{2} \star B_{1} \star C_{1}, S_{2}=A_{2} \star B_{3} \star C_{1}, S_{3}=A_{2} \star B_{4} \star C_{1}$ (resultant quality level equals 2 );

(b) $N=(2 ; 2,1,0): S_{4}=A_{2} \star B_{13} \star C_{1}$ (resultant quality level equals 3 ).

For other combinations of DA's for considered here $A, B$ and $C$ priority will equal 4 and for all others resultant quality level will equal 5 . Here resultant quality level 1 is impossible, e.g., the ideal decision from the viewpoint of earthquake engineering is absent. A reason of this situation consists in the following: filler walls and partitioning walls are not ideal ones. We can obtain an ideal decision if the above-mentioned walls will 
Table 3

Compatibility for $D$

\begin{tabular}{cccccc}
\hline & $G_{1}$ & $G_{2}$ & $H_{1}$ & $H_{2}$ & $H_{3}$ \\
\hline$E_{1}$ & 3 & 2 & 3 & 1 & 2 \\
$E_{2}$ & 2 & 1 & 2 & 1 & 2 \\
$G_{1}$ & & & 3 & 2 & 1 \\
$G_{2}$ & & & 2 & 1 & 1 \\
\hline
\end{tabular}

Table 4

Compatibility for $F$

\begin{tabular}{lllll}
\hline & $I_{1}$ & $I_{2}$ & $I_{3}$ & $I_{4}$ \\
\hline$J_{1}$ & 1 & 2 & 3 & 3 \\
$J_{2}$ & 1 & 1 & 1 & 1 \\
$J_{3}$ & 1 & 2 & 3 & 3 \\
\hline
\end{tabular}

Table 5

Compatibility for $B$

\begin{tabular}{ccccccccccccc}
\hline & $F_{1}$ & $F_{2}$ & $F_{3}$ & $F_{4}$ & $F_{5}$ & $F_{6}$ & $F_{7}$ & $F_{8}$ & $F_{9}$ & $F_{10}$ & $F_{11}$ & $F_{12}$ \\
\hline$D_{1}$ & 3 & 3 & 3 & 2 & 2 & 2 & 2 & 2 & 2 & 2 & 2 & 3 \\
$D_{2}$ & 2 & 2 & 2 & 2 & 2 & 2 & 2 & 2 & 2 & 2 & 2 & 2 \\
$D_{3}$ & 2 & 2 & 2 & 2 & 2 & 2 & 2 & 2 & 2 & 2 & 2 & 2 \\
$D_{4}$ & 2 & 2 & 2 & 2 & 2 & 2 & 2 & 2 & 2 & 2 & 2 & 2 \\
$D_{5}$ & 2 & 2 & 2 & 2 & 2 & 2 & 2 & 2 & 2 & 2 & 2 & 2 \\
$D_{6}$ & 2 & 2 & 2 & 2 & 2 & 2 & 2 & 2 & 2 & 2 & 2 & 2 \\
$D_{7}$ & 2 & 2 & 2 & 2 & 2 & 2 & 2 & 2 & 2 & 2 & 2 & 2 \\
$D_{8}$ & 2 & 2 & 2 & 2 & 2 & 2 & 2 & 2 & 2 & 2 & 2 & 2 \\
$D_{9}$ & 2 & 2 & 2 & 2 & 2 & 2 & 2 & 2 & 2 & 2 & 2 & 2 \\
$D_{10}$ & 2 & 2 & 2 & 2 & 2 & 2 & 2 & 2 & 2 & 2 & 2 & 2 \\
$D_{11}$ & 1 & 1 & 1 & 3 & 2 & 2 & 3 & 2 & 2 & 2 & 2 & 2 \\
$D_{12}$ & 2 & 2 & 2 & 2 & 2 & 2 & 2 & 2 & 2 & 2 & 2 & 2 \\
\hline
\end{tabular}

Table 6

Compatibility for $S$

\begin{tabular}{cccccccc}
\hline & $C_{1}$ & $C_{2}$ & $C_{3}$ & $B_{1}$ & $B_{3}$ & $B_{4}$ & $B_{13}$ \\
\hline$A_{1}$ & 2 & 2 & 2 & 2 & 2 & 2 & 1 \\
$A_{2}$ & 3 & 2 & 2 & 3 & 3 & 3 & 2 \\
$A_{3}$ & 2 & 2 & 2 & 2 & 2 & 2 & 1 \\
$C_{1}$ & & & & 3 & 3 & 3 & 2 \\
$C_{2}$ & & & & 3 & 3 & 3 & 2 \\
$C_{3}$ & & & & 2 & 2 & 2 & 3 \\
\hline
\end{tabular}




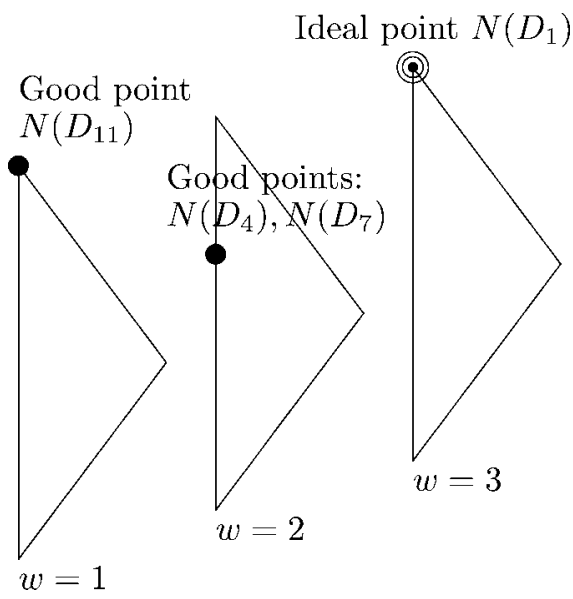

Fig. 13. System excellence for $D$.

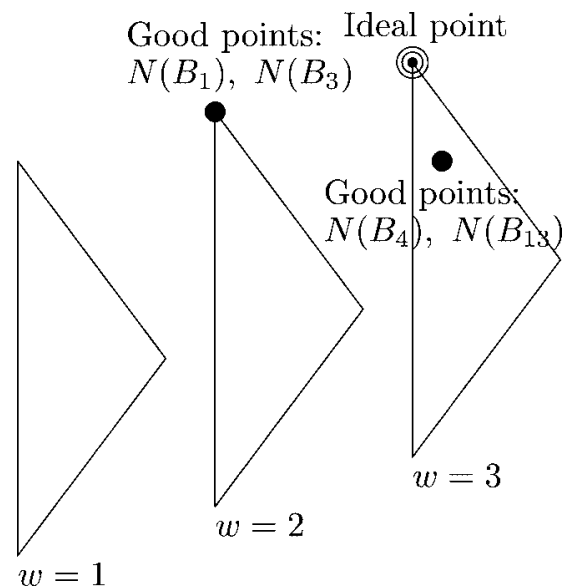

Fig. 15. System excellence for $B$.

Ideal points: $N\left(F_{7}\right), N\left(F_{10}\right)$

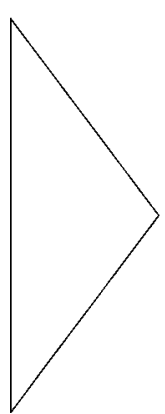

$w=1$

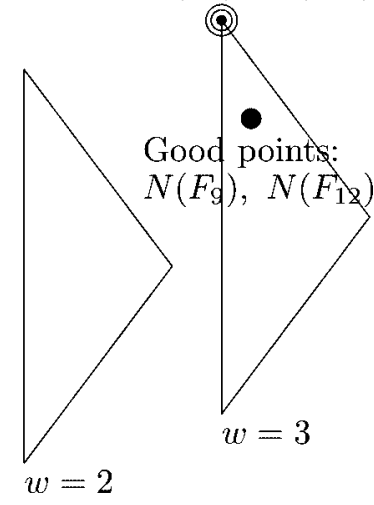

Fig. 14. System excellence for $F$.

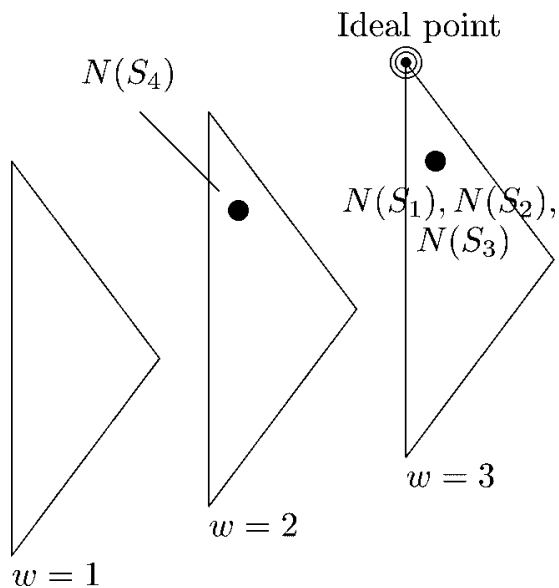

Fig. 16. System excellence for $S$.

be designed as monolith concrete. But in this case, we will get another kind of building structure: building with monolith concrete walls which are strengthening by frames. Note the obtained building will have an increased weight and a decreased level of thermotechnic and acoustic properties. A way to an ideal decision is based on the usage of monolith light concrete or light composite non-structural elements.

Thus we get an ordinal scale for composite DA's $[1, \ldots, 5]$, (1 corresponds to the best level). Let us consider the following examples:

(i) $S^{i}=A_{2} \star\left(E_{1} \star G_{1} \star H_{1}\right) \star\left(I_{3} \star J_{1}\right) \star C_{1}$, resultant quality level equals 2 ;

(ii) $S^{i i}=A_{2} \star\left(E_{2} \star G_{2} \star H_{2}\right) \star\left(I_{3} \star J_{1}\right) \star C_{1}$, resultant quality level equals 2 ;

(iii) $S^{i i i}=A_{1} \star\left(E_{2} \star G_{2} \star H_{2}\right) \star\left(I_{3} \star J_{1}\right) \star C_{3}$, resultant quality level equals 3 ;

(iv) $S^{i v}=A_{2} \star\left(E_{2} \star G_{2} \star H_{2}\right) \star\left(I_{3} \star J_{1}\right) \star C_{3}$, resultant quality level equals 3 ;

(v) $S^{v}=A_{1} \star\left(E_{2} \star G_{1} \star H_{1}\right) \star\left(I_{3} \star J_{3}\right) \star C_{3}$, resultant quality level equals 4 . 


\subsection{Improvement Actions and Criteria}

Our list of the basic improvement actions (operations) for the example is the following:

Operation group I (frames):

1. Increasing a geometrical dimension and active reinforcement $O_{1}$.

2. Increasing of active reinforcement $\mathrm{O}_{2}$.

Operation group II (joints):

3. Increasing a level for fixing a longitudinal active reinforcement in zone of joints $\mathrm{O}_{3}$.

4. Decreasing the step of reinforced cross rods in zone of joint $O_{4}$.

Operation group III (cantilever and cantilever balcony):

5. Decreasing the projection cantilever $\mathrm{O}_{5}$.

6. Supplementary supporting the cantilever $O_{6}$.

Operation group IV (fronton and parapet wall):

7. Fixing a bottom part $O_{7}$.

8. Designing a 3D structure (special) $O_{8}$.

Operation group $\mathbf{V}$ (connection between frame and filler walls):

9. Design of shear keys $O_{9}$.

10. Design of mesh reinforcement $O_{10}$.

11. Partition of filler walls by auxiliary frame $O_{11}$.

Application of several redesign operations is depicted in Fig. 9.

Binary relations on the above-mentioned operations are the following:

(1) equivalence $R^{e}=\{(1,2),(1,3),(1,4),(2,3),(2,4),(5,6),(7,8),(9,10)$,

$(9,11),(10,11)\}$, nonequivalence $\widetilde{R}^{e}=\{(3,4)\}$;

(2) complementarity $R^{c}=\{(1,2),(1,3),(1,4),(1,5),(1,6),(1,7),(1,8)$,

$(1,9),(1,10),(1,11),(2,3),(1,4),(1,5),(1,6),(1,7),(1,8)$,

$(3,4),(3,5),(3,6),(3,7),(3,8)(3,9),(3,10),(3,11),(4,5),(4,6),(4,7),(4,8)$,

$(4,9),(4,10),(4,11),(5,7),(5,8),(5,9),(5,10),(5,11)$,

$(6,7),(6,8),(6,9),(6,10),(6,11),(7,9),(7,10),(7,11)$,

$(8,9),(8,10),(8,11)\}$

noncomplementarity $\widetilde{R}^{c}=\{(5,6),(7,8),(9,10),(9,11),(10,11)\}$; and

(3) precedence $R^{p}=\{(1,2)(1,3)(1,4)(1,5),(1,6),(1,7),(1,8),(1,9)$,

$(1,10),(1,11),(2,3)(2,4)(2,5),(2,6),(2,7),(2,8),(2,9),(2,10),(2,11)$,

$(3,5),(3,6),(3,7),(3,8),(3,9),(3,10),(3,11),(4,5),(4,6),(4,7)$,

$(4,8),(4,9),(4,10),(4,11),(5,9),(5,10),(5,11),(6,9),(6,10)$,

$(6,11),(7,9),(7,10),(7,11),(8,9),(8,10),(8,11)\}$.

The following criteria are considered (corresponded ordinal scales and criterion weights are pointed out in brackets):

\section{Improvement of earthquake resistance:}

1. Decreasing a dead weight (or loading) $([-2, \ldots, 2], 3): K_{1}$.

2. Increasing a load capacity $([1, \ldots, 5], 5): K_{2}$.

3 . Increasing a reliability $([1, \ldots, 5], 5): K_{3}$. 


\section{Quality of architecture and plan decisions:}

4. Facade $([0, . .5],-3):, K_{4}$.

5. Plan $([0, \ldots, 4],-3): K_{5}$.

6. Free space $([0, . ., 2],-3): K_{6}$.

\section{Utilization properties:}

7. Thermotechnics $([0, . ., 2],-1): K_{7}$.

8. Acoustics $([0,1],-1): K_{8}$.

9. Fire-risk $([0,1,2],-4): K_{9}$.

\section{Expenditure:}

10. Materials $([0, . ., 10],-3): K_{10}$.

11. Cost $([0, \ldots, 10],-4): K_{11}$.

12. Time expenditure $([0, \ldots, 10],-3): K_{12}$.

Table 7 contains expert estimates for the above-mentioned building improvement actions upon criteria and a resultant priority (rank).

\subsection{Improvement Process}

The structure (model) of the process is based on binary relation $R^{c}$ as follows: (a) operations for frame (e.g., $O_{1}, O_{2}$ ); (b) operations for joints (e.g., $O_{3}, O_{4}$ ); (c) operations for parapet wall (e.g., $\mathrm{O}_{5}, \mathrm{O}_{6}$ ); (d) operations for cantilever balcony (e.g., $O_{7}, O_{8}$ ); and (e) operations for connection between frame and filler wall (e.g., $O_{9}, O_{10}, O_{11}$ ).

Note precedence of the above-mentioned operation groups is the following: (a); (b); (c) and (d) concurrently; (e). Binary relation $R^{c}$ is a basis to generate the following aggregated operations: $O_{1} \& O_{2}$ and $O_{3} \& O_{4}$. Binary relation $\widetilde{R}^{c}$ is a reason to delete the

Table 7

Estimates of improvement actions

\begin{tabular}{lrcccccccccccc}
\hline \multirow{2}{*}{$\begin{array}{l}\text { Improvement } \\
\text { actions }\end{array}$} & \multicolumn{10}{c}{ Criteria } & \multicolumn{10}{c}{ Rank } \\
\cline { 2 - 11 }$O_{1}$ & $K_{1}$ & $K_{2}$ & $K_{3}$ & $K_{4}$ & $K_{5}$ & $K_{6}$ & $K_{7}$ & $K_{8}$ & $K_{9}$ & $K_{10}$ & $K_{11}$ & $K_{12}$ & \\
$O_{2}$ & 0 & 5 & 5 & 1 & 3 & 2 & 0 & 0 & 0 & 5 & 5 & 5 & 3 \\
$O_{3}$ & 0 & 2 & 3 & 0 & 0 & 0 & 0 & 0 & 0 & 1 & 1 & 1 & 2 \\
$O_{4}$ & 0 & 3 & 4 & 0 & 0 & 0 & 0 & 0 & 0 & 2 & 3 & 3 & 1 \\
$O_{5}$ & 2 & 2 & 4 & 3 & 4 & 1 & 1 & 1 & 1 & 0 & 0 & 0 & 3 \\
$O_{6}$ & -1 & 3 & 5 & 5 & 1 & 1 & 0 & 0 & 2 & 5 & 4 & 5 & 4 \\
$O_{7}$ & 2 & 3 & 4 & 0 & 0 & 0 & 0 & 0 & 1 & 1 & 2 & 2 & 1 \\
$O_{8}$ & 1 & 4 & 5 & 2 & 1 & 1 & 0 & 0 & 1 & 2 & 3 & 4 & 2 \\
$O_{9}$ & 0 & 2 & 3 & 0 & 0 & 0 & 0 & 0 & 1 & 1 & 1 & 1 & 3 \\
$O_{10}$ & 0 & 3 & 4 & 0 & 0 & 0 & 0 & 0 & 1 & 4 & 3 & 4 & 2 \\
$O_{11}$ & 0 & 2 & 4 & 0 & 0 & 0 & 2 & 1 & 0 & 5 & 5 & 5 & 3 \\
$O_{1} \& O_{2}$ & -2 & 5 & 5 & 1 & 3 & 2 & 0 & 0 & 0 & 8 & 8 & 8 & 4 \\
$O_{3} \& O_{4}$ & 0 & 3 & 4 & 0 & 0 & 0 & 0 & 0 & 0 & 3 & 4 & 4 & 2 \\
\hline
\end{tabular}


following aggregated operations $O_{5} \& O_{6}, O_{7} \& O_{8}, O_{9} \& O_{10}, O_{9} \& O_{11}, O_{10} \& O_{11}$, and $O_{9} \& O_{10} \& O_{11}$. The structure of the multi-stage improvement/redesign process and generated operations are shown in Fig. 17. All pointed out operations are compatible (by relation $R_{c}$ ).

Now let us consider the usage of models for the design of the improvement strategy:

Knapsack problem: The usage of knapsack problem is based on independence of the items/operations $\left(\left\{O_{1}, \ldots, O_{11}\right\}\right)$, the only one objective function (mainly), and quantitative nature of the required resources. In our case, we can examine the following problem formulation:

(i) objective function: improvement of earthquake resistance, i.e., criterion $K_{1}$ or $K_{2}$ or $K_{3}$;

(ii) restrictions for resources: (a) quality of architecture and plan decisions: $K_{4}, K_{5}$, and $K_{6}$; (b) utilization properties: $K_{7},\left(K_{8}\right)$, and $K_{9}$; and (c) expenditure: materials $\left(K_{10}\right)$, cost $\left(K_{11}\right)$, time $\left(K_{12}\right)$;

Unfortunately, our redesign operations are interconnected (i.e., binary relations of equivalence, complementarity, and precedence) and it is reasonable to use more complicated model.

Multiple choice problem: In this case, we can consider the approach to problem formulation from the previous section while taking into account operation grouping (Fig. 17), i.e., the structure of the redesign process. In addition, here it is necessary to define resource restrictions for each operation group. Note quantitative scales are basic ones for this model.

Multiple criteria ranking: Table 7 contains the results of multicriteria selection (ranks of operations). This model is the basic one in multicriteria decision making and can be recommended and a significant part of more general solving schemes.

Morphological clique problem: This approach is based on multicriteria ranking and taking into account operation dependence or the structure of the redesign process (Fig. 17). Evidently, here the best redesign strategy is the following: $O_{2} \Rightarrow O_{4} \Rightarrow$ $O_{5} \& O_{7} \Rightarrow O_{10}$.

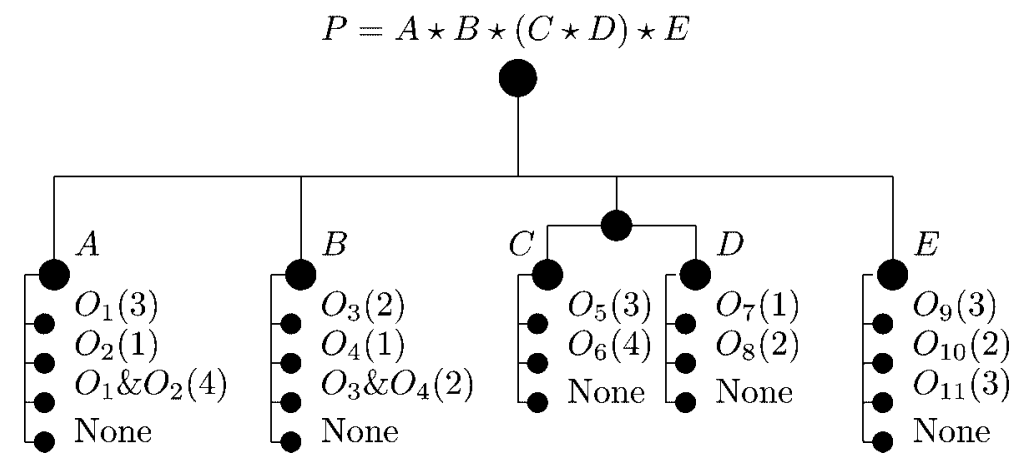

Fig. 17. Structure of redesign process (priorities are shown in brackets). 


\section{Conclusion}

Recently, issues of evaluation and improvement of complex systems play often a central role in many engineering domains (e.g., software engineering, electrical engineering, structural engineering). This process (i.e., evaluation and improvement/redesign or adaptation) can be considered and used in two modes: off-line mode and on-line mode. In this article, we have suggested the general hierarchical decision making framework for the evaluation and improvement/redesign of composite systems. The material consists of the following main parts:

Part 1. Description of Hierarchical Morphological Multicriteria Design which realizes "partitioning/synthesis macroheuristic" and applications for three design problems: (i) hierarchical modular design, (ii) hierarchical assessment of composite systems; and

(iii) improvement/redesign of composite systems.

Part 2. Brief description of the integration tables method for hierarchical system assessment.

Part 3. Framework for system improvement/redesign. The third part involves the following:

1. Design of hierarchical system model.

2. Hierarchical evaluation of the system.

3. Revelation of bottlenecks.

4. Design of improvement processes including the following: 4.1. generation of improvement action set and its description via special binary relations and multicriteria estimates; 4.2. selection/composition of the best subset of the improvement actions while taking into account certain design and technological requirements; and 4.3. scheduling of the selected improvement actions. Several combinatorial optimization models (knapsack problem, multiple choice problem, multiple criteria ranking, and morphological clique problem) are used for the design of improvement processes.

The above-mentioned general hierarchical framework is illustrated by the numerical example of a two-floor building. Future investigations include the following:

I. Examination and enhancement of the hierarchical framework, Hierarchical Morphological Multicriteria Design and "partitioning/synthesis macroheuristic" including the following issues: (i) complexity of the combinatorial problems and computing procedures, (ii) participation of domain experts in all stages of the solving process, (iii) development of a special interactive environment.

II. Investigation of off-line and on-line improvement processes for applied composite systems in various engineering domains.

III. Educational efforts (i.e., special courses and projects as the evaluation and improvement/redesign of applied composite systems).

\section{Acknowledgments}

Early versions of the material were prepared in 1999-2003. At this stage, Mark Sh. Levin was with The College of Judea \& Samaria and The Ben-Gurion University of the Negev (Israel). 


\section{References}

Agarwal, A., J.T. Davis and T. Ward (2001). Supporting ordinal four-state classification decisions using neural networks. Inform. Techn. and Manage., 2(1), 5-26.

Aiello, R., A. Esposito and G. Nota (2002). A hierarchical measurement framework for the evaluation of automated business processes. Int. J. of Software Engineering and Knowledge Engineering, 12(4), 331-361.

Arnold, G., and R. Reitherman (1982). Building Configuration and Seismic Design. Wiley, New York.

Austin, S.A., A.N. Baldwin, B. Li, and P. Waskett (1999). Analytical design planning technique: A model of the detailed building design process. Design Studies, 20(3), 279-296.

Baglivo, J.A., and J.E. Graver (1983). Incidence and Symmetry in Design and Architecture. Cambridge University Press, Cambridge, UK.

Baldwin, A.N., S.A. Austin, S.A. Hassan and T.M. Thorpe (1999). Modelling information flow during the conceptual and schematic stages of building design. Construction Manage. \& Economics, 17(2), 155-167.

Baldwin, C.Y., and K.B. Clark (2000). Design Rules: The Power of Modularity. MIT Press, Cambridge, MA.

Belkin, A.R., and M.Sh. Levin (1990). Decision Making: Combinatorial Models of Information Approximation. Nauka, Moscow (in Russian).

Berman, O., D.I. Ingco and A. Odoni (1994). Improving the location of minimax facilities through network modification. Networks, 24, 31-41.

Bertero, V.V. (1992). Seismic upgrading of existing structures. In Proc. of the 10th World Congress of Earthquake Engineering, Vol. 9. Madrid. pp. 5101-5106.

Beskow, C., and S. Ritzen (2000). Performing changes in product development: A framework with keys for industrial applications. Res. in Eng. Des., 12(3), 172-190.

Blazewicz, J., K.H. Ecker, G. Schmidt and J. Weglarz (1994). Scheduling in Computer and Manufacturing Systems, 2nd ed. Springer, Berlin.

Bowman, I.T., M.W. Godfrey and R.C. Holt (2000). Connecting architecture reconstruction frameworks. Inform. and Software Technol., 42(2), 91-102.

Budnitz, R.J., G. Apostolakis, D.M. Boore, L.S. Cluff, K.J. Coppersmith, C.A. Cornell and P.A. Morris (1998). Use of technical expert panels: applications to probabilistic seismic hazard analysis. Risk Analysis, 18(4), 463-470.

Buede, D.M. (1992). Software review. Overview of MCDA software market. J. of Multi-Criteria Dec. Analysis, 1(1), 59-61.

Buede, D.M. (1999). The Engineering Design of Systems: Models and Methods. Wiley, New York.

Chakravarty, A.K. (1999). Profit margin, process improvement and capacity decisions in global manufacturing. Int. J. of Prod. Res., 37(18), 4235-4257.

Chao, C.J., and F.P. Cheng (1996). A fuzzy diagnostic model for diagnosis cracks in reinforced concrete structures. Microcomputers in Civil Eng., 11, 115-122.

Cheng, F.Y., and Y.Y. Wang (Eds.) (1996). Post-Earthquake Rehabilitation and Reconstruction. Pergamon Press, New York.

Cook, W.D., and M. Kress (1992). Ordinal Information and Preference Structures: Decision Models and Applications. Prentice Hall, Englewood Cliffs, NJ.

Davidovici, V. (1993). Strengthening of existing buildings. In 17th Eur. Seminar on Earthquake Eng. Haifa. pp. 389-415.

Dixon, J.R. (1987). On research methodology towards a scientific theory of engineering design. AI EDAM, 1(3), $145-157$.

Dixon, L.A., and J.S. Colton (2000). A process management strategy for re-design: an anchoring adjustment approach. J. of Eng. Des., 11(2), 159-174.

Du Bois, Ph., J.P. Brans, F. Cantraine and B. Mareschal (1989). MEDICS: An expert system for computer-aided diagnosis using the PROMETHEE multicriteria method. Eur. J. Oper. Res., 39, 284-292.

Engelhardt, F. (2000). Improving systems by combining axiomatic design, quality control tools and design experiments. Res. in Eng. Des., 12(4), 204-219.

Ericsson, A., and G. Erixon (2000). Controlling Design Variants: Modular Product Platforms. ASME Press, New York.

Erol, K., J. Hendler and D. Nau (1996). Complexity results for hierarchical task-network planning. Annals of Math. and AI., 18, 69-93. 
Finger, S., and J.R. Dixon (1989). A review of research in mechanical engineering design. Part II: Representation, analysis, and design for the life cycle. Res. in Eng. Des., 1(2), 121-137.

Fischer, G., M. Makowski and J. Antoine (1996). Multiple Criteria Land Use Analysis. Working Paper WP-96006, Int. Inst. for Applied Systems Analysis.

Fishman, G.S. (1996). Monte Carlo: Concepts, Algorithms, and Applications, 2nd ed. Springer, New York.

Flood, I., N. Gagarin and N. Kartam (1998). Modelling earthquake accelerogramms using neural networks and linear predictors. AI EDAM, 12(3), 243-258.

Floudas, C.A. (1995). Nonlinear and Mixed-Integer Optimization: Fundamentals and Applications (Topics in Chemical Engineering). Oxford University Press, New York.

Fogliatto, F.S., and S.L. Albin (2001). A hierarchical method for evaluation products with quantitative and sensory characteristics. IEE Trans., 33(12), 1081-1092.

Forster, J., P. Fothergill, J.A. Lacunza and I. Arana (1995). DEKLARE: knowledge acquisition and support for re-design. In M.A. Bramen, J.L. Nealon and R. Milne (Eds.), Research and Development in Expert Systems XII - Proc. of Expert Systems'95, Proc. of The 15th Annual Technical Conf. of British Society Specialist Group on Expert Systems. SGES Publications, Cambridge. pp. 23-40.

Fothergill, P., J. Forster, J.A. Lacunza, F. Plaza and I. Arana (1995). A methodological approach to re-design. In K. Baricani, P. MacConail and K. Tierney (Eds.), Proc. of Conf. on Integration in Manufacturing. IOS Press, Vienna. pp. 109-122.

Garey, M.R., and D.S. Johnson (1979). Computers and Intractability. The Guide to the Theory of NPCompleteness. W.H. Freeman and Company, San Francisco.

Ganza, M. (1999). Housing: New Alternatives, New Systems. Princeton Architectural Press, New York.

Gertsbakh, I. (2000). Reliability Theory with Applications to Preventive Maintenance. Springer, Berlin.

Glotov, V.A., and V.V. Paveljev (1984). Vector Stratification. Nauka, Moscow (in Russian).

Gonzalez-Zugasti, J., J. Baker and K. Otto (2000). A method for architecting product platform to interplanitary mission design. Res. in Eng. Des., 12(2), 61-72.

Grossmann, I.E. (1990). Mixed-integer non-linear programming techniques for the synthesis of engineering systems. Res. in Eng. Des., 1(2/3), 205-228.

Gunasekaran, A., A.R. Korukonda, I. Virtanen and P. Yli-Olli (1994). Improving productivity and quality in manufacturing organizations. Int. J. of Prod. Economics, 36(2), 169-183.

Haimes, Y.Y. (1982). Modeling of large scale systems in a hierarchical-multiobjective framework. In Y.Y. Haimes (Ed.), Large Scale Systems. North Holland, Amsterdam. pp. 1-17.

Hameri, A.-P., and J. Nihtila (1998). Computerized product process - measurement and continuous improvement. Res. in Eng. Des., 10(3), 166-177.

Hamlin, G.J., and A.C. Sanderson (1998). Modular Approach to Reconfigurable Parallel Robotics. Kluwer, Boston.

Hazelrigg, G.A. (1996). Systems Engineering: An Approach to Information Based Design. Prentice Hall, NJ.

Hessami, A.G. (1999). Risk management: a systems paradigm. Syst. Eng., 2(3), 156-167.

Hien, W.N., L.K. Poh and H. Feriadi (2000). The use of performance-based simulation tools for building design and evaluation - a singapore perspective. Building and Environment, 35(8), 709-736.

Hon, T., S.K. Chon and T.Y. Bong (2000). Building simulation: An overview of developments and information sources. Building and Environment, 35(4), 347-361.

Hop, F.U. (1988). Modular House Design: The Key to Complete Construction Efficiency. Prentice Hall, NJ.

Hu, Y.X., S.C. Liu and W. Dong (1996). Earthquake Engineering. Chapman and Hall, London.

Huang, C.C., and A. Kusiak (1998). Modularity in design of products and systems. IEEE Trans. on Syst., Man, and Cybern., Part A, 28(1), 66-77.

Hubka, V., and W.E. Eder (1988). Theory of Technical Systems. A Total Concept Theory for Engineering Design. Springer, Berlin.

Hutchings, J.F. (1996). Builder's Guide to Modular Construction. McGraw-Hill, New York.

Isaksson, O., S. Keski-Seppala and S.D. Eppinger (2000). Evaluation of design process alternatives using signal flow graphs. J. of Eng. Des., 11(3), 211-224.

Jones, J.C. (1981). Design Methods. Wiley, New York.

Jonsson, A. (2000). Tools and methods for environments: assessment of building products - methodological analysis of six selected approaches. Building and Environment, 35(13), 223-228.

Kamrani, A.K., and S.M. Salhieh (2000). Product Design for Modularity. Kluwer, Boston. 
Kanda, J., and H. Shah (1997). Engineering role in failure cost evaluation for buildings. Structural Safety, 19(1), 79-90.

Knosala, R., and W. Pedrycz (1992). Evaluation of design alternatives in mechanical engineering. Fuzzy Sets and Syst., 47, 269-280.

Kozin, F., and H.K. Zhou (1988). Systems Study of Urban Response and Reconstruction Due to Catastrophic Earthquake. Technical Report NCEER-88-0027, National Center for Earthquake Engineering Research, Buffalo, N.Y.

Kramer, S.L. (1995). Geotechnical Earthquake Engineering. Prentice-Hall, NJ.

Kuppuraju, N., S. Ganesan, F. Mistree and J.S. Sobieski (1985). Hierarchical decision making in system design. Eng. Optim., 8(3), 223-252.

Kusiak, A. (1999). Engineering Design: Products, Processes, and Systems. Academic Press, New York.

Lagorio, H.J. (1990). Earthquakes: An Architect's Guide to Nonstructural Seismic Hazards. Wiley, New York.

Larichev, O.I., E.M. Moshkovich, E.M. Furems, A.I. Mechitov and V.K. Morgoev (1991). Construction of Full and Contradiction-Free Knowledge Bases. Iec ProGAMMA, The Netherlands.

Levin, M.Sh. (1998). Combinatorial Engineering of Decomposable Systems. Kluwer, Dordrecht.

Levin, M.Sh. (2001). System synthesis with morphological clique problem: fusion of subsystem evaluation decisions. Inform. Fusion, 2(3), 225-237.

Levin, M.Sh., and M.A. Danieli (2000). Framework for evaluation and improvement of buildings. In Proc. of the Intl. Conf. CoDesigning2000, Vol. 2. Univ. of Coventry. pp. 209-214.

Lindell, M.K., and R.W. Perry (1997). Hazardous materials releases in the Northridge earthquake: implications for seismic risk assessment. Risk Analysis, 17(2), 147-156.

Marino, G.G. (1997). Earthquake Damage: Inspection, Evaluation, and Repair. Lawyers \& Judges Publishing Co., New York.

Martello, S., and P. Toth (1990). Knapsack Problem: Algorithms and Computer Implementation. WIley, New York.

Miyasato, G., W. Dong, R. Levitt, and A. Boissounade (1986). Implementation of a knowledge based seismic risk evaluation system on microcomputers. Artificial Intelligence in Eng., 1(1), 29-35.

Naeim, F. (1989). Seismic Design Handbook. Van Nostrand Reinhold, New York.

Neap, H.S., and T. Celik (2001). A knowledge-based system for determination of marginal value of building projects. Expert Syst. with Appl., 21(3), 119-129.

Otto, K.N., and K.L. Wood (2000). Product Design. Prentice Hall, NJ.

Ozer, M. (1999). A survey of new product evaluation models. The J. of Product Innov. Manage., 16(1), 77-94.

Pahl, G., and W. Beitz (1996). Engineering Design: A Systemic Approach, 2nd ed. Springer, London.

Papalambros, P., and N. Michelena (1997). Partitioning in optiml design of large engineering systems. In N. Alexandrov and M. Hussani (Eds.), Multidisciplinary Design Optimization: State-of-the-Art, SIAM. pp. 209-226.

Park, J.H. (2000). Subsymmetry analysis of architectural design: some examples. Environments and Planning. B: Planning and Design, 27(1), 121-136.

Renhorn, A.M. (1999). Toward performance based design in new earthquake engineering standards. In Proc. of The 7th National Congress of Earthquake Engineering, Tel-Aviv. pp. 3-8.

Serzantov, A.V. (1984). On optimal deshiphering algorithm for a monotone function of algebraic logic. Reports of Russian Academy of Sci., 277(2), 204-206 (in Russian).

Shubnikov, A.V., and V.A. Koptsik (1974). Symmetry in Science and Art. Plenum Press, New York.

Simpson, T.W., J.R.A. Maier and F. Mistree (2001). Product platform design: method and application. Res. in Eng. Des., 13(1), 2-22.

Singhal, J., and J.L. Katz (1990). A Branch-And-Fathom algorithm for the long range process design problem. Manage. Sci., 36(4), 513-516.

Sobol, I.M. (1994). A Primer for the Monte Carlo Method. CRC Press, Boca Raton, FL.

Soebarto, V.I., and T.J. Williamson (2001). Multi-criteria assessment of building performance: theory and implementation. Building and Environment, 36(6), 681-690.

Stumptuer, M., and F. Wotawa (2001). Diagnosing tree-structured systems. Artificial Intelligence, 127(1) 1-29.

Tenner, A.R., and I.J. Detoro (1996). Process Redesign: The Implementation Guide for Managers. Prentice Hall, NJ. 
Tsa, C.-H., and D.-S. Hsu (2001). Synthetic damage assessment for RC structure based on fuzzy logic. In L. Monostori, J. Vancza and M. Ali (Eds.), Proc. of IEA/AIE 2001, LNCS 2070. Springer, Berlin. pp. 339 348.

Ulrich, K.T., and S.D. Eppinger (1999). Product Design and Development, 2nd ed. Irwin/McGraw-Hill, New York.

Usher, J.S., A.H. Kamal and W.H. Syed (1998). Cost optimal preventive maintenance and replacement scheduling. IIE Trans., 30, 1121-1128.

Wakabayashi, M. (1984). Design of Earthquake-Resistant Building. McGraw-Hill, New York.

Warshavsky, A., J. Gluck and D. Segal (1996). Economic aspects of seismic design. J. of Structural Eng., ASCE, 122(12), 1400-1408.

Wong, A., and D. Sriram (1993). SHARED: an information model for cooperative product development. Res. in Eng. Des., 5(1), 21-39.

Yerramareddy, S., and S.C.-Y. Lu (1993). Hierarchical and interactive decision: refinement methodology for engineering design. Res. in Eng. Des., 4(4), 227-240.

Yewlett, C.J.L. (2001). OR in strategic land-use planning. J. of the Oper. Res. Soc., 52(1), 4-13.

Zakarian, A., and A. Kusiak (2001). Process analysis and reengineering. Comp. \& Ind. Eng., 41(2), 135-150.

Zwicky, F. (1969). Discovery Invention, Research Through the Morphological Approach. McMillan, New York.

M.Sh. Levin received the MS degree in radioengineering from Moscow Techn. Univ. for Communication and Informatics (1970), the MS degree in mathematics from Moscow State Univ. (1975), and the PhD degree in systems analysis and combinatorial optimization from Inst. for Systems Analysis of Russian Academy of Sciences (1982). Dr. Levin is with Inst. for Information Transmission Problems of Russian Academy of Sciences as a senior scientific researcher. His interests include decision making technology, systems engineering, combinatorial optimization, and applications.

M.A. Danieli received the MS degree in civil engineering from Georgian Polytechnical Univ. (Tbilisi, 1961), the PhD degree in structural engineering from Research Power Engineering and Hydroengineering Inst. (Republic of Georgia, Tbilisi, 1972). Dr. Danieli is a senior lecturer at The College of Judea and Samaria (Israel). His interests include concrete shell structures, seismic design and redesign, and earthquake engineering.

\section{Hierarchinė sprendimu prièmimo struktūra kompozicinėms sistemoms vertinti ir tobulinti (statiniu pavyzdžiu)}

\section{Mark Sh. LEVIN, Moshe A. DANIELI}

Straipsnyje aprašoma sprendimų prièmimo hierarchinè struktūra, skirta vertinti sudètingas sistemas jụ tobulinimo/perprojektavimo metu. Struktūra apjungia hierarchini, morfologini î ir daugiakriterini projektavimą (HMDP), morfologinę grupinę problemą ir atlieka dalinimo arba sintezès makroeuristiką.

Sistemos vertinimo procesas apjungia hierarchini ekspertiniu metodu integravimą: integruojamu lenteliu metodą arba morfologini projektavimą. Taip atliekama daugiapakope sutvarkomoji klasifikacija. Sistemos tobulinimo procesas nagrinejamas kaip perprojektavimo operaciju parinkimas ir planavimas ivertinant operaciju (procesu) charakteristikas ir binarinius ryšius operaciju aibèms. Sistemos tobulinimo proceso modeliavimui naudojamas keletas kombinatorinès optimizacijos modeliu, iskaitant HMDP.

Siūlomas metodas pritaikytas sprendžiant realų dviaukščio pastato perprojektavimo uždavini, ivertinant, kad statyba numatoma padidinto seismingumo teritorijoje. 